\title{
Side-by-side comparison of the effects of Gq-and Gi-DREADD-mediated astrocyte modulation on intracellular calcium dynamics and synaptic plasticity in the hippocampal CA1
}

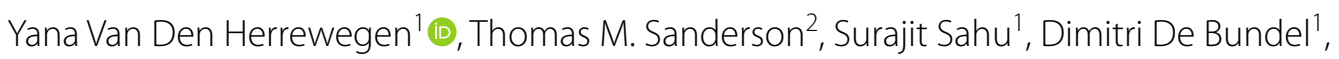
Zuner A. Bortolotto ${ }^{2+}$ and Ilse Smolders ${ }^{1 *+}$

\begin{abstract}
Astrocytes express a plethora of $G$ protein-coupled receptors (GPCRs) that are crucial for shaping synaptic activity. Upon GPCR activation, astrocytes can respond with transient variations in intracellular $\mathrm{Ca}^{2+}$. In addition, $\mathrm{Ca}^{2+}$-dependent and/or $\mathrm{Ca}^{2+}$-independent release of gliotransmitters can occur, allowing them to engage in bidirectional neuron-astrocyte communication. The development of designer receptors exclusively activated by designer drugs (DREADDs) has facilitated many new discoveries on the roles of astrocytes in both physiological and pathological conditions. They are an excellent tool, as they can target endogenous GPCR-mediated intracellular signal transduction pathways specifically in astrocytes. With increasing interest and accumulating research on this topic, several discrepancies on astrocytic $\mathrm{Ca}^{2+}$ signalling and astrocyte-mediated effects on synaptic plasticity have emerged, preventing a clear-cut consensus about the downstream effects of DREADDs in astrocytes. In the present study, we performed a side-by-side evaluation of the effects of bath application of the DREADD agonist, clozapine-N-oxide $(10 \mu \mathrm{M})$, on Gq- and Gi-DREADD activation in mouse CA1 hippocampal astrocytes. In doing so, we aimed to avoid confounding factors, such as differences in experimental procedures, and to directly compare the actions of both DREADDs on astrocytic intracellular $\mathrm{Ca}^{2+}$ dynamics and synaptic plasticity in acute hippocampal slices. We used an adeno-associated viral vector approach to transduce dorsal hippocampi of male, 8-week-old C57BL6/J mice, to drive expression of either the Gq-DREADD or Gi-DREADD in CA1 astrocytes. A viral vector lacking the DREADD construct was used to generate controls. Here, we show that agonism of Gq-DREADDs, but not Gi-DREADDs, induced consistent increases in spontaneous astrocytic $\mathrm{Ca}^{2+}$ events. Moreover, we demonstrate that both Gq-DREADD as well as GiDREADD-mediated activation of CA1 astrocytes induces long-lasting synaptic potentiation in the hippocampal CA1 Schaffer collateral pathway in the absence of a high frequency stimulus. Moreover, we report for the first time that astrocytic Gi-DREADD activation is sufficient to elicit de novo potentiation. Our data demonstrate that activation of
\end{abstract}

\footnotetext{
*Correspondence: Ilse.smolders@vub.be

tZuner A. Bortolotto and Ilse Smolders contributed equally and share last authorship

${ }^{1}$ Department of Pharmaceutical Chemistry, Drug Analysis and Drug Information, Research Group Experimental Pharmacology, Center

for Neurosciences (C4N), Vrije Universiteit Brussel (VUB), Laarbeeklaan 103,

1090 Brussels, Belgium

Full list of author information is available at the end of the article
} permits use, sharing, adaptation, distribution and reproduction in any medium or format, as long as you give appropriate credit to the original author(s) and the source, provide a link to the Creative Commons licence, and indicate if changes were made. The images or other third party material in this article are included in the article's Creative Commons licence, unless indicated otherwise in a credit line to the material. If material is not included in the article's Creative Commons licence and your intended use is not permitted by statutory regulation or exceeds the permitted use, you will need to obtain permission directly from the copyright holder. To view a copy of this licence, visit http://creativecommons.org/licenses/by/4.0/. The Creative Commons Public Domain Dedication waiver (http://creativeco mmons.org/publicdomain/zero/1.0/) applies to the data made available in this article, unless otherwise stated in a credit line to the data. 
either $\mathrm{Gq}$ or Gi pathways drives synaptic potentiation through $\mathrm{Ca}^{2+}$-dependent and $\mathrm{Ca}^{2+}$-independent mechanisms, respectively.

Keywords: Astrocytes, Chemogenetics, DREADDs, Calcium imaging, Long-term potentiation, LTP, Hippocampus, Schaffer collateral

\section{Introduction}

Astrocytes are one of the most abundant resident cells of the brain, well known for providing metabolic support, ensuring homeostasis, and maintaining the blood-brain barrier. Astrocytes express a wide array of G proteincoupled receptors (GPCRs), allowing them to respond to synaptic activity. Indeed, astrocytes have emerged as key players at quad-partite synapses and were found to actively participate in bidirectional neuron-astrocyte communication via transient variations in intracellular $\mathrm{Ca}^{2+}[1,2]$ and the release of gliotransmitters, such as glutamate, $\gamma$-aminobutyric acid (GABA), and/or adenosine triphosphate (ATP)/adenosine (reviewed by $[3,4]$ ). Astrocytic $\mathrm{Ca}^{2+}$ signaling generally remains a complex and poorly understood concept [2] and is often dysregulated in various CNS disorders [5-9]. Therefore, it is of utmost importance to understand how astrocytes tune neuronal activity and modulate higher brain functions, as this can aid in the discovery of potential novel therapeutic strategies for multiple brain disorders. It is well-established that increases in astrocytic $\mathrm{Ca}^{2+}$ transients can be elicited by activation of Gq-coupled GPCRs [3, 10-13]. This astrocytic Gq-GPCR activation recruits a similar downstream intracellular cascade as observed in response to Gq-GPCR activation in neurons. Briefly, astrocytic Gq-GPCR activation recruits the Goq protein, which in turn leads to 1,4,5-trisphosphate $\left(\mathrm{IP}_{3}\right)$-mediated $\mathrm{Ca}^{2+}$ release from internal stores [13]. In contrast, although there is evidence of a role of $\mathrm{Gi}$ GPCR signalling in astrocytes, the nature of the signalling has been less consistently reported in the literature. Canonically, Gi-GPCR activation recruits the $\mathrm{G}_{\alpha i / o}$ protein which inhibits adenylate cyclase and thus, reduces intracellular cyclic adenosine monophosphate (cAMP), while the $G \beta \gamma$ subunit activates inwardly rectifying $\mathrm{K}^{+}$ channels and/or inhibits $\mathrm{Ca}^{2+}$ channels [14]. Indeed, a reduction in cAMP has been reported upon Gi-GPCR activation in astrocytes [15], suggesting that these receptors are coupled to the expected $\mathrm{G}_{\text {ai/o }}$ protein. Regarding the effect on intracellular $\mathrm{Ca}^{2+}$, either no effect on $\mathrm{Ca}^{2+}$ levels [16] or decreased baseline $\mathrm{Ca}^{2+}$ levels, presumed to be the resulting action of the G $\beta \gamma$ subunit [17], have been reported after Gi-GPCR activation in hippocampal [16] and ventral midbrain astrocytes [16, 17], respectively. However there is also ample evidence showing an increase in astrocytic $\mathrm{Ca}^{2+}$ transients upon Gi-GPCR activation, such as activation of $\mathrm{GABA}_{\mathrm{B}} \mathrm{Rs}$ and dopamine D1 and D2-type receptors in the hippocampus [18-21], $\mathrm{GABA}_{\mathrm{B}} \mathrm{Rs}$ in the somatosensory cortex [22], $\mathrm{GABA}_{\mathrm{B}}$ Rs in the ventral tegmental area [23] and the $\mu$-opioid receptor (MOR) and dopamine D1 receptors in the nucleus accumbens $[24,25]$. Moreover, these $\mathrm{GABA}_{\mathrm{B}} \mathrm{R}$ and MORinduced increases in cytosolic $\mathrm{Ca}^{2+}$ were suggested to be derived from intracellular stores [19, 22, 24, 26], as these $\mathrm{Ca}^{2+}$ transients were shown to be abolished in inositol 1,4,5-trisphosphate receptor type $2\left(\mathrm{IP}_{3} \mathrm{R} 2\right)$ knock-out mice $[19,22,24]$ or when $\mathrm{IP}_{3}$-gated internal $\mathrm{Ca}^{2+}$ stores were depleted $[19,26]$. The underlying mechanisms mediating astrocytic $\mathrm{Ca}^{2+}$ transients via Gi-GPCR activation remain elusive. In addition, activation of either Gq- or Gi-GPCRs on astrocyte surfaces impact synaptic transmission and plasticity via either $\mathrm{Ca}^{2+}$-dependent $[10,19,27-31]$ or $\mathrm{Ca}^{2+}$-independent gliotransmitter release $[16,32]$. Interestingly, the magnitude and temporal characteristics of astrocyte-mediated synaptic modulation, were found to be significantly affected by the pattern of interneuron activity, that caused GABA release and in turn stimulated hippocampal astrocytic $\mathrm{GABA}_{\mathrm{B}} \mathrm{Rs}$ [33]. This means that astrocytes can interpret and integrate time- and frequency-related variations in stimulation and, thus suggests that differences in experimental protocols related to GPCR agonist application, such as duration and concentration, could potentially complicate correct interpretation of the obtained results.

Unfortunately, further investigation of reciprocal neuron-astrocyte interactions have long been hindered due to the lack of selective tools to modulate astrocytic GPCR signalling [34, 35]. Designer receptors exclusively activated by designer drugs (DREADDs) are an interesting tool to tackle these issues as they use GPCR-mediated intracellular signal transduction pathways naturally present in astrocytes. DREADDs have been increasingly used to study effects on intracellular GPCR-dependent astrocytic $\mathrm{Ca}^{2+}$ signalling and on synaptic transmission and/or plasticity. Similar to endogenous GPCRs, Gq- and Gi-coupled DREADDs have both been shown to induce $\mathrm{Ca}^{2+}$ responses in astrocytes [36-42]. However, while Gq-DREADD-induced astrocyte modulation is consistently reported to increase astrocytic $\mathrm{Ca}^{2+}$ events or baseline $\mathrm{Ca}^{2+}$ levels [36-42], the effect of Gi-DREADDs on astrocytic $\mathrm{Ca}^{2+}$ signalling remains less clear [39, 40, 43]. Differences in intracellular $\mathrm{Ca}^{2+}$ responses upon 
Gi-DREADD mediated astrocyte modulation have been reported, not only between brain regions [40], but also within the same region i.e., hippocampus [39, 40, 43]. More specifically, application of the DREADD agonist, clozapine-N-oxide (CNO), to hippocampal slices transduced with Gi-DREADD has been shown alternately to elicit transient increases in intracellular $\mathrm{Ca}^{2+}$ [39], to decrease intracellular baseline $\mathrm{Ca}^{2+}$ levels [43] or to have no discerable effect [40].

To date, only a limited amount of evidence has been gathered regarding gliotransmitter release upon Gq- or Gi-DREADD activation in hippocampal astrocytes. For instance, slow inward currents (SICs) in surrounding neurons were observed upon $\mathrm{CNO}$ bath application in hippocampal slices expressing either astrocytic Gq-DREADD or Gi-DREADD [39], which is typically attributed to the activation of extrasynaptic neuronal $\mathrm{N}$-methylD-aspartate receptors (NMDARs) via astrocytic released glutamate [44]. Interestingly, Chai et al. [40] did not observe any changes in SIC amplitude or frequency, nor did they observe increased glutamate release using a genetically encoded glutamate sensor (iGluSnFR) upon CNO bath application in Gq-DREADD transduced hippocampal astrocytes. In addition, the release of D-serine has been implied upon astrocytic Gq-DREADD activation [36]. It is however accepted that activation of both Gq- and Gi-coupled DREADDs can alter hippocampal synaptic plasticity [16, 36, 39, 43]. For instance, Gq-DREADD-mediated astrocytic activation was found to induce long-term potentiation (LTP) in the Cornu Ammonis 1 (CA1) of the hippocampus without any additional, subthreshold electrical stimulus [36], while Gi-DREADD activation was proposed to reduce LTP threshold, as LTP was induced solely upon application of an additional 40-Hz stimulus [16].

In this research paper we compare in parallel Gq- and Gi-DREADD-mediated activation of hippocampal astrocytes and evaluate their effects on intracellular $\mathrm{Ca}^{2+}$ dynamics in astrocytes and synaptic plasticity in the hippocampal CA1 Schaffer collateral pathway. In addition, we emphasize the importance of reporting the application duration and concentration of DREADD agonists, to allow proper comparison of the effects on astrocytic $\mathrm{Ca}^{2+}$ and synaptic plasticity in ex vivo slices.

\section{Materials and methods}

\section{Animals}

All experiments were performed on male C57BL/6J mice (Charles River Laboratories, UK), 8 weeks old at the time of surgery. All mice were group-housed in a temperature $\left(19-23{ }^{\circ} \mathrm{C}\right)$ and humidity (30-70\% relative humidity) regulated environment with a 12/12 h light/dark cycle and received food pellets and water ad libitum. Mice were habituated 1 week to the animal house upon arrival and were subsequently subjected to surgery. All procedures involving animals were conducted in accordance with the Animal Scientific Procedures Act 1986, UK, and with approval of the University of Bristol. To the best of our abilities, results were reported in accordance with the ARRIVE guidelines [45].

\section{Viral vector transduction}

Astrocyte-specific expression of the DREADDs was obtained using an adeno-associated viral (AAV) vector expressing either the Gq- or Gi-DREADD fused to the red fluorescent protein mCherry under the GFAP promotor (Gq-DREADD: vector AAV8-GFAP-hM3DqmCherry, diluted 1:50 with sterile saline with a final concentration of $2.96 \times 10^{12} \mathrm{gc} / \mathrm{ml}$, plasmid \#50478 acquired from Addgene; Gi-DREADD: vector AAV8-GFAPhM4Di-mCherry, diluted 1:50 with sterile saline with a final concentration of $2.46 \times 10^{12} \mathrm{gc} / \mathrm{ml}$, plasmid \#50479 acquired from Addgene); or the control vector AAV8GFAP-mCherry (undiluted $2.7 \times 10^{12} \mathrm{vg} / \mathrm{ml}$, obtained from UNC Vector Core by Dr. Boyden).

Mice were anesthetized with isoflurane and received s.c. $2 \mathrm{mg} / \mathrm{kg}$ lidocaine $\left(2 \%\right.$ Xylocaine ${ }^{\circledR}$ Solution injectable, Aspen, UK), s.c. $5 \mathrm{mg} / \mathrm{kg}$ carprofen $(50 \mathrm{mg} / \mathrm{ml}$, Rimadyl ${ }^{\circledR}$ Small Animal Solution for Injection, Pfizer, USA) and $0.9 \% \mathrm{NaCl}$ (Baxter) to assure appropriate pain killing and hydration. After disinfection of the skin with Isobetadine ${ }^{\circledR}$, an incision was made from between the eyes until the end of the skull. Using a stereotactic microinjection system, bilateral hippocampal infusion of an AAV vector (500 $\mathrm{nl}$ per injection site) was performed at the following coordinates relative to Bregma (anteroposterior (AP), $-1.5 \mathrm{~mm}$, mediolateral (ML), $\pm 1 \mathrm{~mm}$, dorsoventral (DV), $-1.6 \mathrm{~mm}$; site 2: AP $-2.5 \mathrm{~mm}, \mathrm{ML}$ $\pm 2 \mathrm{~mm}, \mathrm{DV}-1.6 \mathrm{~mm}$ ). The syringe was maintained in place for an additional $10 \mathrm{~min}$. to limit back flow along the injection track. After injection, the skin was closed using nonabsorbable suturing material (Ethilon II, 4-0, M-2, Ethicon). Mice were group housed and sacrificed for ex vivo experiments 3-5 weeks after surgery to ensure full expression of the DREADDs.

\section{Chemicals}

CNO, a DREADD agonist, was acquired from Enzo LifeSciences (Belgium). CNO is dissolved in DMSO at a concentration of $30 \mathrm{mM}$. Stock solution is diluted to reach a final working concentration of $10 \mu \mathrm{M}$ in artificial cerebrospinal fluid (aCSF). Oregon Green ${ }^{\text {TM }} 488$ BAPTA-1 acetoxymethyl ester (OGB-1 AM) was obtained from ThermoFischer Scientific (USA). The $\mathrm{Ca}^{2+}$-dye was prepared as described in [46]: to each $50 \mu \mathrm{g}$-vial of the dye, $3.87 \mu \mathrm{l}$ of dimethyl sulfoxide (DMSO) and $9 \mu \mathrm{l}$ of a $20 \%$ 
(w/v) Pluronic F-127 (ThermoFischer Scientific, Rockford, USA) was added and was maintained in an ultrasound bath for $15 \mathrm{~min}$. Right before dye-loading, this solution was mixed with $100 \mu \mathrm{l}$ artificial cerebrospinal fluid (aCSF) and filtered.

\section{Hippocampal slice preparation}

Acute coronal hippocampal slices were prepared from 11-13 weeks old male, C57Bl6/J mice, previously injected with viral vectors driving DREADD-hM3Dq or DREADD-hM4Di or control vector expression in their astrocytes. All mice were killed by cervical dislocation according to Schedule 1 of the United Kingdom (Scientific Procedures) Act of 1986. Brains were rapidly removed and placed into ice-cold sucrose-containing aCSF (87 mM NaCl, $75 \mathrm{mM}$ sucrose, $25 \mathrm{mM} \mathrm{NaHCO}_{3}$, $2.5 \mathrm{mM} \mathrm{KCl}, 1.25 \mathrm{mM} \mathrm{NaH}_{2} \mathrm{PO}_{4}, 7 \mathrm{mM} \mathrm{MgCl}, 0.6 \mathrm{mM}$ ascorbic acid, $0.5 \mathrm{mM} \mathrm{CaCl}_{2}$, and $25 \mathrm{mM}$ D-glucose) oxygenated with $95 \% \mathrm{O}_{2}$ and $5 \% \mathrm{CO}_{2}$. Slices were cut using a vibratome (Leica VT1200).

\section{Ex vivo calcium imaging}

Coronal $300-\mu \mathrm{m}$ sections were incubated for $45 \mathrm{~min}$ at $35{ }^{\circ} \mathrm{C}$ in a holding chamber with continuously oxygenated low $\mathrm{Ca}^{2+}$-aCSF $(124 \mathrm{mM} \mathrm{NaCl}, 26 \mathrm{mM} \mathrm{NaHCO}$, $3 \mathrm{mM} \mathrm{KCl}, 1.4 \mathrm{mM} \mathrm{NaH}{ }_{2} \mathrm{PO}_{4}, 6 \mathrm{mM} \mathrm{MgSO}, 1 \mathrm{mM}$ $\mathrm{CaCl}_{2}$, and $12 \mathrm{mM}$ D-glucose; $\left.\pm 310 \mathrm{mOsm}\right)$ and afterwards kept for two additional hours at room temperature in normal aCSF $\left(124 \mathrm{mM} \mathrm{NaCl}, 26 \mathrm{mM} \mathrm{NaHCO}_{3}, 3 \mathrm{mM}\right.$ $\mathrm{KCl}, 1.4 \mathrm{mM} \mathrm{NaH}_{2} \mathrm{PO}_{4}, 1 \mathrm{mM} \mathrm{MgSO}$, $2 \mathrm{mM} \mathrm{CaCl}_{2}$, and $10 \mathrm{mM}$ D-glucose). Slices were then transferred to a submerged recording chamber $\left(28{ }^{\circ} \mathrm{C}\right)$, continuously perfused with aCSF $(2 \mathrm{ml} / \mathrm{min})$, and bolus loading of Oregon Green BAPTA-1 AM calcium dye was performed. A glass pipette filled with the dye solution was lowered into the stratum radiatum of the slice, and the dye was ejected twice ( $5 \mathrm{psi}$ ) for $3 \mathrm{~min}$. at two locations $100 \mu \mathrm{m}$ from each other. After dye loading, slices were allowed to rest for an additional $30 \mathrm{~min}$, enabling intracellular dyeuptake. Images were acquired at $1.1 \mathrm{frame} / \mathrm{s}$ using a Zeiss LSM510 two-photon confocal microscope. The imaging protocol was based on [36]; shortly, after 5-min baseline recording, CNO $(10 \mu \mathrm{M})$ was bath-applied for a total duration of $35 \mathrm{~min}$. During this period, 5-min recordings were alternated with 5 -min 'rest' periods to avoid photo bleaching. After $35 \mathrm{~min}, \mathrm{CNO}$ was washed-out and imaging was paused for $20 \mathrm{~min}$. Subsequently alternated imaging re-started for an additional period of $30 \mathrm{~min}$ (Fig. 1a).

$\mathrm{Ca}^{2+}$-imaging analysis was performed using Image $(\mathrm{NIH})$ and changes in fluorescence intensity were recorded by drawing analysis boxes over individual astrocytic cell bodies. $\mathrm{Ca}^{2+}$-events were defined if peak amplitude was larger than 3 standard deviations (SD) above the mean of average baseline fluorescence for 2 consecutive data points or more $(\Delta \mathrm{F} / \mathrm{F} 0)$.

\section{Ex vivo slice electrophysiology}

Extracellular field recordings were performed in CA1 following [36]. Briefly, 400- $\mu \mathrm{m}$ coronal slices were incubated for $30 \mathrm{~min}$. at $35{ }^{\circ} \mathrm{C}$ and then kept for $1 \mathrm{~h}$ at room temperature in a holding chamber with oxygenated normal aCSF $\left(124 \mathrm{mM} \mathrm{NaCl}, 26 \mathrm{mM} \mathrm{NaHCO}_{3}, 3 \mathrm{mM} \mathrm{KCl}\right.$, $1.4 \mathrm{mM} \mathrm{NaH} \mathrm{PO}_{4}, 1 \mathrm{mM} \mathrm{MgSO}_{4}, 2 \mathrm{mM} \mathrm{CaCl}$, and $10 \mathrm{mM}$ D-glucose). Slices were then transferred to a submerged recording chamber $\left(28^{\circ} \mathrm{C}\right)$. Extracellular synaptic activity was measured using a bipolar tungsten electrode to deliver stimuli (frequency of $0.033 \mathrm{~Hz}$ ) to the Schaffer collateral pathway, evoking field excitatory postsynaptic potentials (fEPSPs) recorded from a $3 \mathrm{M} \mathrm{NaCl}$-containing glass microelectrode (3-5 M $\Omega$ ) in the stratum radiatum of CA1 (Fig. 2a). Amplitude of fEPSPs were recorded on-line using the WinLTP software [47]. After obtaining stable responses, slices were incubated in aCSF containing $10 \mu \mathrm{M} \mathrm{CNO}$ for $25 \mathrm{~min}$, allowing evaluation of the effect of $\mathrm{CNO}$ on synaptic plasticity (Fig. 2b). The amplitude of fEPSPs in CA1 was monitored for at least $30 \mathrm{~min}$ following wash-out. All slices were viewed under the Zeiss LSM510 confocal fluorescent microscope to verify DREADD-mCherry expression.

\section{Statistics}

Analyses, statistical evaluation and presentation of the data were performed with Prism v7.0 (GraphPad Software, Inc.). Multiple groups of data were analysed by Repeated Measures (RM) Two-Way analysis of variance (ANOVA) followed by the Bonferroni test for post-hoc comparisons. All tests were performed with $\alpha=0.05$. $p$ values $<0.05$ were considered significant. All results are expressed as means \pm SEM.

\section{Results \\ Gq-DREADD, but not Gi-DREADD, activation in hippocampal astrocytes induces transient increases in astrocytic $\mathrm{Ca}^{2+}$ events}

To investigate long-term effects (35 $\mathrm{min})$ on astrocytic $\mathrm{Ca}^{2+}$-transients exerted by activation of either Gq- or Gicoupled DREADDs by the designer drug CNO, ex vivo two-photon $\mathrm{Ca}^{2+}$ imaging was performed. To this end, hippocampal slices from C57BL/6J mice were used, that had been previously injected with viral vectors driving expression of either Gq-DREADDs, Gi-DREADDs or mCherry (in case of control viral vector) in $\mathrm{GFAP}^{+}$cells. The effect on spontaneous astrocytic $\mathrm{Ca}^{2+}$ events during 5-min imaging epochs before, during and after $\mathrm{CNO}$ (10 $\mu \mathrm{M}, 35 \mathrm{~min}$ ) bath application was assessed (Fig. 1a), using OGB-1 AM as fluorescent $\mathrm{Ca}^{2+}$ indicator (Fig. 1b). 


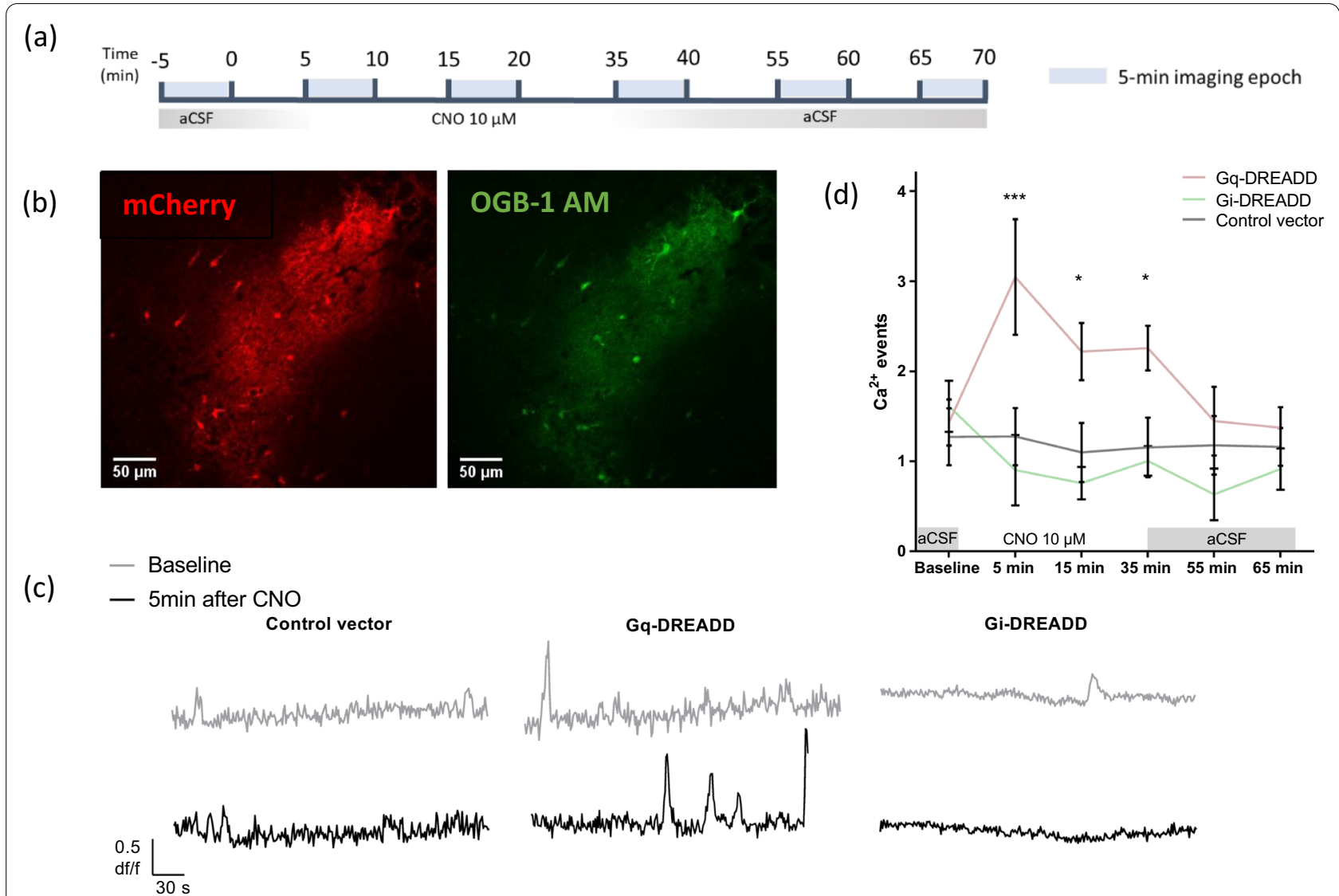

Fig. 1 Spontaneous $\mathrm{Ca}^{2+}$ events during 5-min periods following long-term chemogenetic manipulation of astrocytes. a Timeline overview of the experimental procedure. $\mathbf{b}$ Two-photon confocal image of CA1 astrocytes expressing DREADDs, fused to an mCherry protein for visualization (red) and the fluorescent $\mathrm{Ca}^{2+}$ indicator OGB-1 AM (green). Scale bar of $50 \mu \mathrm{m}$ is marked in white. c Representative traces of individual astrocytes before and 5 min after CNO application. Graph (d) shows the average amount of $\mathrm{Ca}^{2+}$ events per 5-min imaging periods recorded from CA1 astrocytes before, during and after CNO $(10 \mu \mathrm{M})$ application. RM Two-Way ANOVA shows a significant difference between groups. Bonferroni's post-hoc analysis shows significant differences in the Gq-DREADD transduced mice 5 to $35 \mathrm{~min}$ after CNO application compared to control transduced slices (control vector vs. Gq-DREADD; 5 min after $C N O p=0.0006 ; 15$ min after CNO, $p=0.0377 ; 35$ min after CNO, $p=0.0410 ; G q-D R E A D D, n=5$; control vector, $n=4$ ), while no significant differences were observed for the Gi-DREADD during nor after CNO application (Bonferroni's post-hoc analysis, control vector vs. Gi-DREADD; 5 min after $C N O p=0.8973 ; 15$ min after $C N O, p=0.9766 ; 35$ min after $C N O, p>0.9999 ; 20$ min after wash-out, $p=0.5380 ; 30$ min after wash-out, $p>0.9999 ; n=4) .{ }^{*} p<0.05 ;{ }^{* *} p<0.001$. Data are represented as the mean $\pm S E M, G q-D R E A D D, n=5$; Gi-DREADD, $n=4$; and control vector, $n=4$

RM Two-Way ANOVA showed a significant interaction $(\mathrm{F}(10,50)=3.995, \mathrm{p}=0.0005, \mathrm{n}=4-5)$, a significant time effect $(\mathrm{F}(5,50)=3.224, \mathrm{p}=0.0134, \mathrm{n}=4-5)$, and a main DREADD effect $(\mathrm{F}(2,10)=4.294, \mathrm{p}=0.0451, \mathrm{n}=4-5)$. Specifically, after 5-min CNO bath application, Gq-DREADD-expressing astrocytes showed elevated intracellular $\mathrm{Ca}^{2+}$ transients $(3.05 \pm 0.64, \mathrm{n}=5)$ (Fig. 1c). Significant increases in $\mathrm{Ca}^{2+}$ events were observed throughout the entire duration of $\mathrm{CNO}$ application in Gq-coupled-DREADD-expressing slices (Fig. 1d, Bonferroni's post-hoc analysis, control vector vs. Gq-DREADD; $5 \mathrm{~min}$ after $\mathrm{CNO}$ $\mathrm{p}=0.0006 ; 15 \mathrm{~min}$ after $\mathrm{CNO}, \mathrm{p}=0.0377 ; 35 \mathrm{~min}$ after $\mathrm{CNO}, \mathrm{p}=0.0410 ; \mathrm{n}=4-5)$ and only returned to baseline after wash-out (Fig. 1d, Bonferroni's post-hoc analysis, control vector vs. Gq-DREADD; 20 min after wash-out, $\mathrm{p}>0.999 ; 30 \mathrm{~min}$ after $\mathrm{CNO}, \mathrm{p}>0.999 ; \mathrm{n}=4-5)$. CNO did not significantly affect spontaneous $\mathrm{Ca}^{2+}$ events in GiDREADD-expressing astrocytes $(0.90 \pm 0.39, \mathrm{n}=4)$ nor control vector transduced astrocytes $(1.27 \pm 0.32, \mathrm{n}=4)$ (Fig. 1c). Importantly, in Gi-DREADD-expressing slices no significant difference in astrocytic $\mathrm{Ca}^{2+}$ events were recorded during $\mathrm{CNO}$ application nor after wash-out, compared to slices transduced with the control vector (Fig. 1d, Bonferroni's post-hoc analysis, control vector vs. Gi-DREADD; 5 min after CNO $\mathrm{p}=0.8973 ; 15 \mathrm{~min}$ after $\mathrm{CNO}$, $\mathrm{p}=0.9766 ; 35 \mathrm{~min}$ after $\mathrm{CNO}, \mathrm{p}>0.9999 ; 20 \mathrm{~min}$ after wash-out, $\mathrm{p}=0.5380 ; 30 \mathrm{~min}$ after wash-out, $\mathrm{p}>0.9999$; $\mathrm{n}=4$ ). Our data shows that bath application of $10 \mu \mathrm{M} \mathrm{CNO}$ 


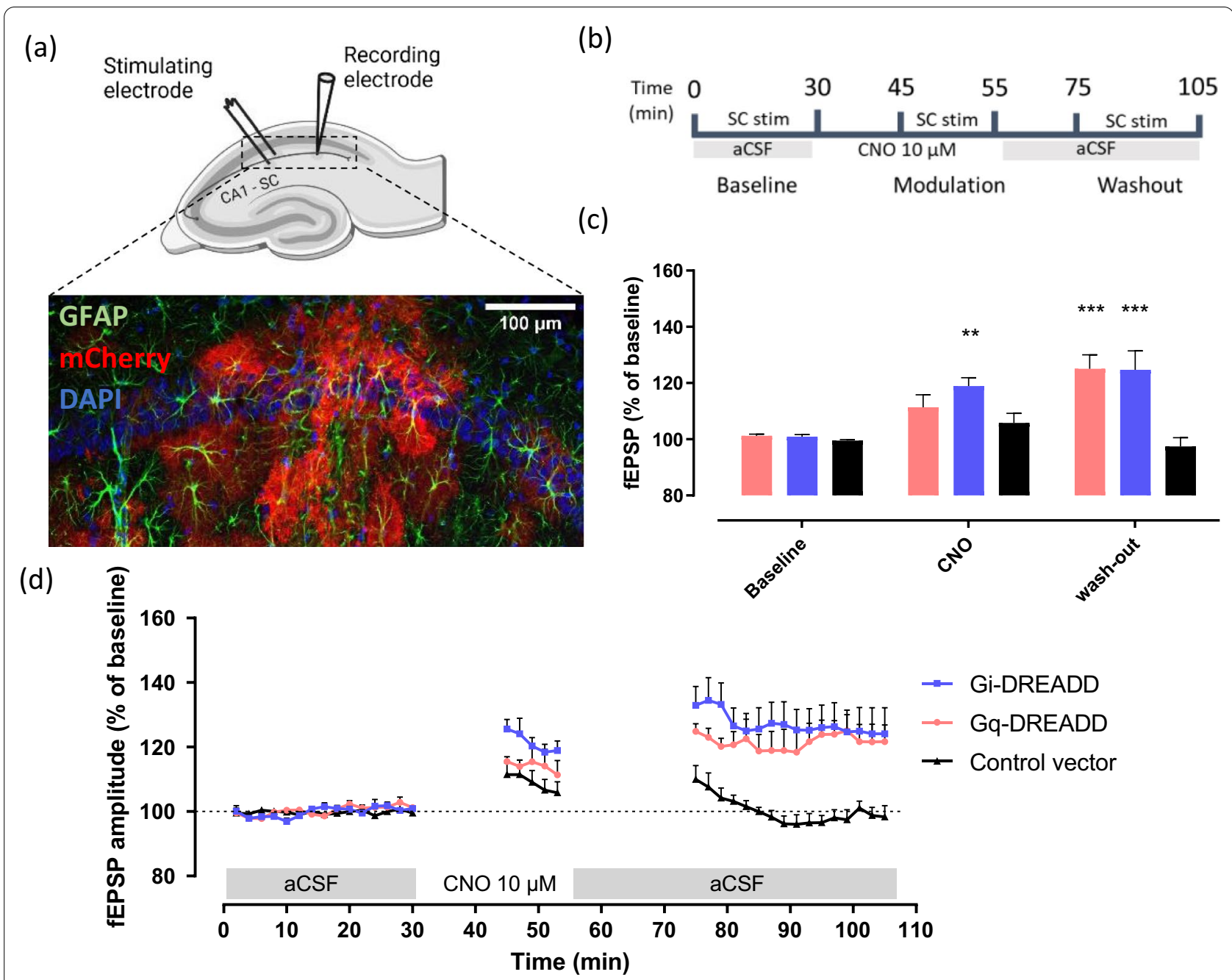

Fig. 2 The effect of Gq-and Gi-DREADD activation in hippocampal astrocytes on plasticity of CA1 synapses. a Schematic overview of the electrode positions during CA1-Schaffer collateral stimulation (positioned $0.5 \mathrm{~mm}$ apart, created with BioRender.com). Immunohistochemistry showed CA1 astrocytes (GFAP, green) expressing DREADDs, which are fused to an mCherry protein (mCherry, red) and cell nuclei (DAPI, blue). Scale bar of $100 \mu \mathrm{m}$ is marked in white. $\mathbf{b}$ Schematic timeline of the experimental procedure. Graph (c) shows the average fEPSP amplitude of the last stimulation in every phase of the experiment (baseline, CNO and wash-out). Comparisons between baseline and CNO or wash-out were made for every group using RM Two-Way ANOVA Bonferroni's Post-hoc analysis, and significant results are illustrated on the graph with an asterisk, ${ }^{* *} \mathrm{p}<0.01 ;{ }^{* * *} \mathrm{p}<0.001$. d The graph shows the amplitude of the fEPSPs recorded from Schaffer Collateral (SC) stimulation in CA1 in time upon CNO (10 $\mu$ M) application. Data are represented as the mean $\pm S E M, G q-D R E A D D, n=4$; Gi-DREADD, $n=4$; and control vector, $n=5$

for 35 min elicits robust, spontaneous increases in $\mathrm{Ca}^{2+}$ transients in Gq-DREADD-expressing astrocytes, which return to baseline after changing the perfusion medium to CNO-free, normal aCSF, while Gi-DREADDs trigger a $\mathrm{Ca}^{2+}$-independent intracellular pathway upon activation.

\section{Both Gq- and Gi-DREADD activation in hippocampal astrocytes induces potentiation at hippocampal CA1 synapses in absence of high frequency stimulation} Subsequently, we examined the effect of either astrocytic Gq- or Gi-DREADD-mediated modulation on synaptic transmission at Schaffer collateral neuronal synapses in area CA1 (Fig. 2a). More specifically, using extracellular field potential recordings, we monitored the effect on low frequency $(0.033 \mathrm{~Hz})$ evoked synaptic events before, during and after CNO $(10 \mu \mathrm{M})$ bath application, as previously described for Gq-DREADD activation [36]. In short, after obtaining stable baseline responses, the DREADD agonist CNO $(10 \mu \mathrm{M})$ was applied to the bath and recordings were stopped for $15 \mathrm{~min}$. Next, $0.033 \mathrm{~Hz}$ Schaffer collateral stimulation and field recordings resumed for 10 min during continuous $\mathrm{CNO}$ perfusion. 
Finally, perfusion medium was switched to $\mathrm{CNO}$-free, normal aCSF to allow wash-out of $\mathrm{CNO}$ and recordings were paused again, only to be resumed $20 \mathrm{~min}$ after (Fig. 2b).

RM Two-Way ANOVA showed a significant interaction $(\mathrm{F}(4,30)=5.427, \mathrm{p}=0.0021 ; \mathrm{n}=4-5)$, a significant time effect $(\mathrm{F}(2,30)=15.00, \mathrm{p}<0.0001 ; \mathrm{n}=4-5)$ and a DREADD effect $(\mathrm{F}(2,30)=14.24, \mathrm{p}<0.0001 ; \mathrm{n}=4-5)$. Strikingly, in our set-up, during CNO application, we observed a significant increase in fEPSP amplitude for Gi-DREADD expressing slices compared to baseline (Fig. 2c, d; Post-hoc Bonferroni's multiple comparisons test, Gi-DREADD baseline vs. CNO $\mathrm{p}=0.0047$ ). As expected, fEPSP amplitude for control vector transduced slices during $\mathrm{CNO}$ application did not differ significantly compared to baseline (Fig. 2c, d; Post-hoc Bonferroni's multiple comparisons test; control baseline vs. CNO $\mathrm{p}=0.3738$ ). Yet, a small transient increase in amplitude of fEPSPs in control transduced slices can be observed after resuming stimulation, which is commonly reported upon interruption of evoked potentials [48]. In addition, fEPSP elicited in Gi-DREADD expressing hippocampal slices differed significantly from control transduced slices during $\mathrm{CNO}$ application (Fig. 2c, d; Post-hoc Bonferroni's multiple comparisons test; Gi-DREADD CNO vs. control CNO $\mathrm{p}=0.0371$ ). For Gq-DREADD expressing slices, a trend towards increased fEPSP amplitude during $\mathrm{CNO}$ application was observed compared to baseline (Fig. 2c, d; Post-hoc Bonferroni's multiple comparisons test, Gq-DREADD baseline vs. CNO p $=0.1383)$. Interestingly, both Gq-DREADD $(125.08 \pm 4.96 \%, \mathrm{n}=4)$ and Gi-DREADD $(124.69 \pm 6.77 \%, \mathrm{n}=4)$ expressing hippocampal slices, but not control slices $(97.45 \pm 3.13 \%$, $\mathrm{n}=5$ ), exhibited significant potentiation after changing the perfusion medium to CNO-free, normal aCSF, which was long-lasting (>30 min) (Fig. 2c, d Post-hoc Bonferroni's multiple comparisons test, Gq-DREADD baseline vs. wash-out $\mathrm{p}=0.0002$; Gi-DREADD baseline vs. washout $\mathrm{p}=0.0002$; control baseline vs. wash-out $\mathrm{p}=0.8961$ ).

As such, our data suggests that activation of either Gqor Gi-coupled DREADDs on astrocytes is able to induce long-term (>30 min) synaptic potentiation at hippocampal CA1 neuronal synapses in the absence of high frequency stimulation and that activation of the Gi-coupled DREADDs is sufficient to induce de novo potentiation.

\section{Discussion}

In the past few years, chemogenetic approaches have been used to evaluate the crucial role of astrocytes in higher brain functions and this has drastically broadened our understanding of these star-like cells. However, proficient comprehension of the intracellular processes and subsequent effects on the surrounding neuropil are imperative to fully grasp their contribution in physiological and pathological conditions. Ongoing research on this topic unveiled astrocyte-mediated effects on synaptic plasticity $[16,36]$, but also, several inconsistencies on astrocytic $\mathrm{Ca}^{2+}$ signalling $[39,40,43]$ preventing unambiguous characterization of the downstream effects of the DREADDs.

In the present study, we performed a side-by-side comparison of astrocyte activation using the two most commonly used DREADDs, hM3Dq (Gq protein-coupled GPCR) and hM4Di (Gi protein-coupled GPCR), and studied their effects on intracellular astrocytic $\mathrm{Ca}^{2+}$-signalling and synaptic plasticity in the hippocampal CA1 neuronal network. We showed that 35-min application of DREADD agonist CNO $(10 \mu \mathrm{M})$, induced a robust increase in intracellular astrocytic $\mathrm{Ca}^{2+}$ events in Gq-DREADD, but not Gi-DREADD, expressing CA1 hippocampal astrocytes compared to control vector transduced astrocytes. In addition, we showed that both Gq- as well as Gi-mediated astrocyte modulation successfully potentiated synaptic transmission in the Schaffer collateral pathway, which was long-lasting and in the complete absence of any additional high-frequency stimulation.

Our results show that long-term Gq-DREADD activation in astrocytes resulted in a robust long-lasting increase in $\mathrm{Ca}^{2+}$ events, which is in line with the literature [36] and expectations with regard to the well-known downstream signalling upon Gq-coupled GPCRs. In addition, after switching bath perfusion from CNOcontaining aCSF to CNO-free, normal aCSF, the amount of $\mathrm{Ca}^{2+}$ transients returned to baseline, suggesting wash-out of the DREADD agonist. However, we cannot exclude that other mechanisms, such as desensitization of the Gq-DREADD, occur, causing this decrease in $\mathrm{Ca}^{2+}$ transients. Interestingly, upon astrocytic Gi-DREADD activation, different effects on astrocytic $\mathrm{Ca}^{2+}$ have been previously described. For instance, Kol et al. [43] found that Gi-DREADD activation $(10 \mathrm{~min}, 10 \mu \mathrm{M})$ induced a slight decrease in baseline $\mathrm{Ca}^{2+}$ levels of hippocampal astrocytes, while Durkee et al. [39] reported increases in intracellular $\mathrm{Ca}^{2+}$ upon puff application of CNO $(2-5 \mathrm{~s}$, $1 \mathrm{mM})$ in Gi-DREADDs expressing hippocampal astrocytes. In addition, Chai et al. [40] did not find consistent increases in intracellular $\mathrm{Ca}^{2+}$ hippocampal astrocytes during CNO bath application ( 4 min, $1 \mu \mathrm{M})$. Likewise, we observed no changes in the frequency of $\mathrm{Ca}^{2+}$ transients of Gi-DREADD transduced slices following DREADD agonism (35 $\mathrm{min}, 10 \mu \mathrm{M})$. Although, the mechanisms involving such variations on intracellular $\mathrm{Ca}^{2+}$ are hitherto still unknown, we propose that these discrepancies might be ascribed to a difference in astrocyte stimulation intensity, i.e. combination of the concentration and 
duration of the Gi-GPCR agonist application. Intriguingly, recently individual hippocampal astrocytes were found to be able to release both ATP/adenosine and glutamate and this in a time-dependent and activity-sensitive manner upon GABA released during interneuron activity [33]. This suggests that the type and intensity of astrocyte stimulation is crucial in determining which downstream signalling pathway is induced by astrocytic $\mathrm{GABA}_{B} \mathrm{R}$ activation. However, whether this differentiation in downstream signalling pathway upon $G_{A B A} R$ activation affects $\mathrm{Ca}^{2+}$ responses and if this is the case for Gi DREADDs as well, remains to be investigated. Nonetheless, astrocytic Gi-DREADD modulation has been shown to inhibit astrocytic cAMP signalling [49, 50], thus it is reasonable to assume that the hM4Di-DREADD receptor is coupled to the $G_{\alpha i / o}$ protein, but that the $\beta \gamma$ subunits of the $G$ protein act differently upon activation depending on the intensity of stimulation. Interestingly, Gi-DREADD-induced $\mathrm{Ca}^{2+}$ elevations in hippocampal astrocytes upon short-term, high concentration $\mathrm{CNO}$ application, were recently shown to be mediated via direct binding of the $\beta \gamma$ subunits to $\mathrm{IP}_{3} \mathrm{R} 2$ [39].

Next, we investigated the effects of either Gq-DREADD or Gi-DREADD-mediated astrocyte activation on synaptic plasticity in the Schaffer collateral-CA1 hippocampal network. As experimental protocols and slicing conditions can affect the characteristics of cells and networks and, thus experimental outcomes, we lay out the details of the methods provided in two papers focusing on DREADD-based LTP induction [16, 36] in comparison to our experimental procedures, in Table 1. Upon Gq-DREADD activation in hippocampal astrocytes, we observed LTP in the absence of any high frequency electrical stimulus, as previously reported [36]. Significant potentiation of fEPSP responses occurred following the wash-out phase of the DREADD agonist CNO. This is in contrast to observations made by Adamsky et al. [36], who reported a greater magnitude of potentiation that was apparent immediately during the first stimulation after $\mathrm{CNO}$ application. This discrepancy may be explained by differences in experimental set-up (see Table 1). For example, we prepared our slices in sucrose containing cutting solution, a manipulation that has previously been shown to reduce the magnitude of LTP [51].

The most novel finding of our study is the fact that we show for the first time that Gi-DREADD activation of astrocytes induces de novo long-lasting potentiation, as significant increases in fEPSP amplitude were already observed from the first stimulation after $\mathrm{CNO}$ application onwards, which lasted longer than $30 \mathrm{~min}$ after wash-out. Previously, Gi-DREADD activation of hippocampal astrocytes was shown to reduce the threshold of LTP induction, as LTP was elicited when $40-\mathrm{Hz}$ stimulation was performed in addition to $\mathrm{CNO}$ bath application [16]. However, in our study we showed that low-frequency stimulation $(0.033 \mathrm{~Hz})$ is sufficient to evoke LTP. This might be ascribed to variations in astrocytic GPCR stimulation, i.e. duration and concentration of GPCR agonist application, as previously discussed, which can affect outcomes on synaptic plasticity [33]. In addition, other experimental differences, for instance, slice recovery conditions, such as submerging of the slice, in combination with $\mathrm{Mg}^{2+}$ concentrations are critical players in permitting metaplastic effects on LTP duration [52], which were not fully disclosed in [16]. Moreover, $\mathrm{Ca}^{2+}$ uncaging in astrocytes, has also been reported to reduce LTP threshold, and only to induce LTP in combination with an additional depolarization [31]. However, as no effect on astrocytic $\mathrm{Ca}^{2+}$ transients were observed upon Gi-DREADD activation, our data suggests that GiDREADD activation of astrocytes affects synaptic plasticity in $\mathrm{Ca}^{2+}$-independent manner.

Astrocytes actively shape synaptic transmission via release of neuroactive substances, such as gliotransmitters (glutamate, GABA, ATP, adenosine, and d-serine), synaptogenic cues (e.g. thrombospondins, tumor necrosis factor alpha) and metabolic substrates (e.g. lactate, lipids) (reviewed by [53]). The context-specific release of gliotransmitters is regulated via activation of GPCRs, which in turn can induce enhanced $\mathrm{Ca}^{2+}$ transients (reviewed by [54]). Indeed, multiple endogenous astrocytic Gq-GPCRs and Gi-GPCRs have been reported to elicit increases in $\mathrm{Ca}^{2+}$ transients, followed by a release of active substances and/or gliotransmitters $[10,18,19,22,24,27-29,31,55]$. Likewise, activation of the exogenous Gq-DREADDs expressed in hippocampal astrocytes, was previously proposed to induce synaptic potentiation via $\mathrm{Ca}^{2+}$-dependent release of $\mathrm{D}$-serine [36]. The underlying mechanisms of GPCR-induced $\mathrm{Ca}^{2+}$-dependent gliotransmitter release can be divided in two major categories: vesicular exocytosis, relying on soluble $\mathrm{N}$-ethylmaleimidesensitive factor attachment protein receptor (SNARE) complexes $[56,57]$ and non-vesicular release via gliotransmitter-permeable ion channels (such as opening of the $\mathrm{Ca}^{2+}$-regulated Bestrophin-1 channel [58, 59]). Besides $\mathrm{Ca}^{2+}$-dependent release of gliotransmitters, there is some evidence showing that activation of astrocytic GPCRs is able to trigger $\mathrm{Ca}^{2+}$-independent release of gliotransmitters. Particularly, several GiGPCRs, such as the $\mu$-opioid receptor (MOR) $[16,60]$, $\mathrm{GABA}_{\mathrm{B}}$ receptor, cannabinoid receptor 1 , and adenosine 1 receptor [58], have been shown to trigger glutamate release via a $\mathrm{Ca}^{2+}$-independent mechanism upon activation. This $\mathrm{Ca}^{2+}$-independent release of glutamate was found to rely on the interaction of the 
Table 1 Methodological specifications of ex vivo field recordings in the Schaffer collateral pathway, using Gq- and Gi-DREADD based astrocyte modulation

\begin{tabular}{|c|c|c|c|}
\hline & $\begin{array}{l}\text { Current study, Van Den } \\
\text { Herrewegen et al. (2021) }\end{array}$ & Adamsky et al. [36] & Nam et al. [16] \\
\hline \multicolumn{4}{|l|}{ Viral vectors and used chemogenetic tools } \\
\hline Viral vector with DREADD construct & $\begin{array}{l}{ }^{*} \text { Gq-DREADD: AAV8-GFAP-hM3Dq- } \\
\text { mCherry } \\
{ }^{*} \text { Gi-DREADD: AAV8-GFAP-hM4Di- } \\
\text { mCherry } \\
{ }^{*} \text { Control vector: AAV8-GFAP- } \\
\text { mCherry }\end{array}$ & $\begin{array}{l}{ }^{*} \text { Gq-DREADD: AAV8-GFAP-hM3Dq- } \\
\text { mCherry } \\
{ }^{*} \text { Gi-DREADD: / } \\
{ }^{*} \text { Control vector: AAV8-GFAP- } \\
\text { mCherry }\end{array}$ & $\begin{array}{l}{ }^{*} \text { Gq-DREADD: / } \\
{ }^{*} \text { Gi-DREADD: AAV-GFAP-hM4Di- } \\
\text { mCherry } \\
{ }^{*} \text { Control vector: AAV-GFAP-GFP }\end{array}$ \\
\hline \multicolumn{4}{|l|}{ Animals } \\
\hline Mouse strain/age & C57Bl6J/11-13 weeks & C57Bl6J/11-13 weeks & C57Bl6J/7-8 weeks \\
\hline Gender & Male & Male & Male \\
\hline Group/single housed & Group & Group & Ns \\
\hline \multicolumn{4}{|l|}{ Slicing conditions } \\
\hline Slice orientation and thickness & $\begin{array}{l}\text { Coronal } \\
400 \mu \mathrm{m}\end{array}$ & $\begin{array}{l}\text { Coronal } \\
400 \mu \mathrm{m}\end{array}$ & $\begin{array}{l}\text { Transverse } \\
350-400 \mu \mathrm{m}\end{array}$ \\
\hline Slicing solution (in mM) & $\begin{array}{l}75 \text { Sucrose, } 87 \mathrm{NaCl}, 2.5 \mathrm{KCl}, 25 \\
\mathrm{NaHCO}_{3}, 1.25 \mathrm{NaH}_{2} \mathrm{PO}_{4}, 7 \mathrm{MgCl}_{2} \\
0.5 \mathrm{CaCl}_{2}, 0.6 \mathrm{Ascorbic} \text { acid and } 25 \\
\text { glucose }\end{array}$ & $\begin{array}{l}126 \mathrm{NaCl}, 2.6 \mathrm{KCl}, 26 \mathrm{NaHCO}_{3}, 1.25 \\
\mathrm{NaH}_{2} \mathrm{PO}_{4}, 1 \mathrm{MgCl}_{2}, 0.625 \mathrm{CaCl}_{2} \text { and } \\
10 \text { glucose }\end{array}$ & $\begin{array}{l}212.7 \text { sucrose, } 5 \mathrm{KCl}, 26 \mathrm{NaHCO}_{3}, 1.23 \\
\mathrm{NaH}_{2} \mathrm{PO}_{4}, 10 \mathrm{MgSO}_{4}, 0.5 \mathrm{CaCl}_{2} \text {, and } \\
10 \text { dextrose }\end{array}$ \\
\hline Slice recovery conditions & 1 h submerged & $1 \mathrm{~h}$ submerged & $1 \mathrm{hns}$ \\
\hline \multicolumn{4}{|l|}{ DREADD agonist } \\
\hline DREADD agonist & CNO & $\mathrm{CNO}$ & CNO \\
\hline Concentration & $10 \mu \mathrm{M}$ & $10 \mu \mathrm{M}$ & ns \\
\hline Duration of CNO application & $25 \min$ & $25 \mathrm{~min}$ & $10 \mathrm{~min}$ \\
\hline \multicolumn{4}{|c|}{ Slice electrophysiology recording conditions } \\
\hline Stimulation frequency & $0.033 \mathrm{~Hz}$ & $0.017 \mathrm{~Hz}$ & $0.07 \mathrm{~Hz}$ \\
\hline Stimulations during baseline & 30 min (60 stimulations) & 10 min (10 stimulations) & 10 min (40 stimulations) \\
\hline Pause in stimulation & Yes & Yes & No \\
\hline $\begin{array}{l}\text { Stimulations necessary for induc- } \\
\text { tion of synaptic potentiation }\end{array}$ & $\begin{array}{l}\text { Gq-DREADD: } 21 \\
\text { Gi-DREADD: } 1\end{array}$ & $\begin{array}{l}\text { Gq-DREADD: } 1\left(1 \mathrm{mM} \mathrm{Mg}^{2+}\right) \\
21\left(2 \mathrm{mM} \mathrm{Mg}^{2+}\right)\end{array}$ & $\begin{array}{l}\text { Gi-DREADD: } 40+\text { additional } 40 \mathrm{~Hz} \\
\text { stimulus }\end{array}$ \\
\hline Bath temperature & $28^{\circ} \mathrm{C}$ & $32^{\circ} \mathrm{C}$ & $28-30^{\circ} \mathrm{C}$ \\
\hline aCSF composition (in mM) & $\begin{array}{l}124 \mathrm{NaCl}_{1} 3 \mathrm{KCl}, 26 \mathrm{NaHCO}_{3}, 1.4 \\
\mathrm{NaH}_{2} \mathrm{PO}_{4}, 1 \mathrm{MgSO}_{4}, 2 \mathrm{CaCl}_{2} \text { and } 10 \\
\text { glucose }\end{array}$ & $\begin{array}{l}126 \mathrm{NaCl}_{2} 2.6 \mathrm{KCl}, 26 \mathrm{NaHCO}_{3 \prime} \text { ' } \\
1.25 \mathrm{NaH}_{2} \mathrm{PO}_{4}, 1 \mathrm{MgCl}_{2}, 2 \mathrm{CaCl}_{2} \text { and } \\
10 \text { glucose }\end{array}$ & $\begin{array}{l}124 \mathrm{NaCl}_{1} 5 \mathrm{KCl}, 26 \mathrm{NaHCO}_{3}, 1.23 \\
\mathrm{NaH}_{2} \mathrm{PO}_{4}, 1 \mathrm{MgSO}_{4}, 2 \mathrm{CaCl}_{2} \text { and } 10 \\
\text { dextrose }\end{array}$ \\
\hline
\end{tabular}

ns not specified

dissociated $\mathrm{G} \beta \gamma$ complex with the glutamate-permeable, TWIK-related $\mathrm{K}^{+}$(TREK-1) channel i.e., a twopore domain potassium channel [58]. Intriguingly, such $\mathrm{Ca}^{2+}$-independent mediated glutamate release has been shown to affect synaptic plasticity. More specifically, astrocytic MOR activation, co-localized with and known to release glutamate via the TREK-1 channel [60], was shown to induce LTP in the presence of an additional high frequency $(40-\mathrm{Hz})$ stimulus [16]. This effect was ascribed to activation of presynaptic metabotropic glutamate receptors 1 (mGluRs1) and, notably, could be successfully mimicked by activation of Gi-DREADDs in astrocytes [16]. However, also other mediators can be released independent of increases in $\mathrm{Ca}^{2+}$ transients. For instance, activation of astrocytic
mGluR3, a Gi-GPCRs, was recently shown to release prostaglandin $\mathrm{E}_{2}\left(\mathrm{PGE}_{2}\right)$ in the presence of a blocker of the endoplasmic reticulum $\mathrm{Ca}^{2+}$ pump (cyclopiazonic acid). Moreover, they showed that this astrocytic $\mathrm{PGE}_{2}$ release led to altered synaptic plasticity, i.e. enhanced mEPSPs in surrounding neurons [61]. Noteworthy, peripheral astrocytic processes (PAPs) are critically involved in synaptic plasticity and are known to display spotty $\mathrm{Ca}^{2+}$ transients in their microdomains $[27,62,63]$. Although no elevations in $\mathrm{Ca}^{2+}$ transients were observed in our study, assessment of $\mathrm{Ca}^{2+}$ transients was restricted to the soma and large processes, as $\mathrm{Ca}^{2+}$-imaging was performed using two-photon $\mathrm{Ca}^{2+}$ imaging after bolus loading of a chemical dye (OGB-1 AM), which is known to have limited spatial 
resolution [64-66]. Imaging of PAPs typically requires high-resolution and time-consuming imaging techniques, such as $3 \mathrm{D}$ two-photon $\mathrm{Ca}^{2+}$ imaging in combination with genetically-encoded $\mathrm{Ca}^{2+}$ indicator [64] or electron microscopy [66]. Therefore, we cannot fully exclude that there is no $\mathrm{Ca}^{2+}$-dependent process in the PAPs involved in the Gi-DREADD-mediated synaptic plasticity in our experiments. Nevertheless, taken together, these findings emphasize the possibility of Gi-GPCR-mediated $\mathrm{Ca}^{2+}$-independent release of active substances, which in turn can affect synaptic plasticity. Particularly, Gi-GPCR-mediated $\mathrm{Ca}^{2+}$-independent glutamate release via the two-pore domain potassium TREK-1 channel is the most promising mechanism for the observed $\mathrm{Ca}^{2+}$-independent Gi-DREADD-induced de novo potentiation. Notwithstanding, additional data should be gathered to verify if this Gi-DREADDinduced synaptic potentiation is $\mathrm{Ca}^{2+}$-independent.

Our present results suggest that Gq- and Gi-DREADD, based astrocyte modulation, rely on different mechanisms to induce LTP. This postulation is reinforced by the different responses observed during long-term $\mathrm{Ca}^{2+}$ signalling in Gq- and Gi-DREADDed astrocytes. Activation of Gq-DREADDs expressed in astrocytes was previously proposed to induce NMDAR-dependent LTP formation via the release of $\mathrm{D}$-serine [36]. More specifically, slices pre-treated with $10 \mu \mathrm{M}$ D-serine, failed to induce synaptic potentiation upon additional $\mathrm{CNO}$-mediated Gq-DREADD activation, likely due to occlusion [36]. Moreover, another study showed that clamping of intraastrocytic $\mathrm{Ca}^{2+}$ levels suppressed LTP at nearby synapses, which was rescued by adding $10 \mu \mathrm{M}$ D-serine [29]. Taken together, this indicates $\mathrm{Ca}^{2+}$-dependent $\mathrm{D}$-serine from astrocytes release is crucial for LTP induction. On the contrary, previous research showed that activation of Gi-DREADDs in astrocytes lowered the threshold for LTP induction, which was ascribed to astrocytic glutamate release and the subsequent activation of neuronal presynaptic metabotropic glutamate receptors 1 (mGluRs 1) [16]. This is in line with the proposed $\mathrm{Ca}^{2+}$-independent TREK-1 channel-mediated release of glutamate, as these channels were reported to induce a fast release that facilitates high extracellular peak concentrations of glutamate, necessary to activate mGluRs [58]. Agonism of group I mGluRs (mGluR1 and mGluR5) has been previously reported to facilitate LTP [67-69], however an additional mechanism is required to induce de novo LTP in CA1 synapses [70, 71]. It is therefore likely that the observed astrocytic Gi-DREADD-induced de novo potentiation is evoked via an additional mechanism, besides mGluR agonism. Indeed, astrocyte-mediated glutamatergic signalling has been repeatedly reported to induce LTP via various mechanisms in addition to mGluR activation [3, 10]. Moreover, even though TREK-1 channel-mediated glutamate release predominantly activates mGluRs $[16,58,60]$, it was also reported to activate NMDARs [58]. Therefore, it is expected that Gi-DREADD activation in astrocytes induces activation of both glutamate receptors i.e., NMDAR and mGluR, and thus triggers an NMDAR-dependent LTP. Additionally, astrocytes have also been reported to be involved in NMDAR-independent LTP [10]. Specifically, application of acetylcholine induced an NMDAR-independent, cholinergic-LTP in CA3-CA1 synapses. This effect relied on muscarinic acetylcholine receptor (mAChR)-mediated glutamate release from astrocytes, which subsequently activated neuronal mGluRs, in addition to simultaneous depolarization of the postsynaptic neuron [10]. However, in this study, mAChR-mediated glutamate release was shown to rely on increased intracellular $\mathrm{Ca}^{2+}$ in the astrocytic processes [10]. In addition, ATP, shown to be co-released with glutamate from individual hippocampal astrocytes [33], is able to further facilitate LTP induction upon group I mGluR and NMDAR co-activation [72]. Notably, a caveat of the current study is that we cannot fully exclude that the small, but not significant, increase in fEPSP amplitude after a break in the stimulation protocol observed in control slices (Fig. 2d), is crucial for NMDAR co-activation together with Gi-DREADDmediated mGluR1, and thus contributes to Gi-DREADDmediated potentiation. Nonetheless, it should be further investigated to confirm whether Gi-DREADD activation truly elicits an NMDAR-dependent LTP. Therefore, we encourage future research comparing the effects of both DREADDs on synaptic plasticity and to elucidate the underlying mechanisms. Moreover, we wish to emphasize the importance of reporting detailed descriptions of the experimental procedures to avoid discrepancies.

In summary, we showed that Gq-DREADD activation in astrocytes triggered a robust increase in $\mathrm{Ca}^{2+}$ events, which was not observed upon astrocytic Gi-DREADD activation. Importantly, we demonstrated that both Gq-DREADD and Gi-DREADD activation of astrocytes are sufficient to induce long-lasting potentiation of CA1 synapses, even in the absence of high frequency stimulation. In particular, we show that Gi-DREADD activation of hippocampal astrocytes induces de novo potentiation, potentially in a $\mathrm{Ca}^{2+}$-independent manner. Further investigation is required to fully characterize the downstream mechanisms involved in the modulation of intracellular $\mathrm{Ca}^{2+}$ signalling upon $\mathrm{Gi}$ and Gq-DREADD mediated astrocyte activation. Comprehensive knowledge of astrocytic GPCR downstream signalling will help unveil the various roles of the excitatory and inhibitory neuro- and gliotransmitters in the hippocampal network and the resulting effects on brain 
function. Moreover, recent research has put astrocytic DREADD modulation forward as a potential therapeutic strategy in the treatment of CNS diseases [49, 73, 74] and understanding the relevant signalling cascades in physiological conditions will be the first step towards translation to the clinic.

\begin{abstract}
Abbreviations
AAV: Adeno-associated viral vector; aCSF: Artificial cerebrospinal fluid; ATP: Adenosine triphosphate; CA1: Cornu Ammonis 1; CAMP: Cyclic adenosine monophosphate; CNO: Clozapine-N-oxide; DREADDs: Designer receptors exclusively activated by designer drugs; fEPSP: Field excitatory postsynaptic potentials; GABA: $\gamma$-Aminobutyric acid; $G_{A B A} R$ : $\gamma$-Aminobutyric acid receptor B; GPCR: G protein-coupled receptor; $\mathrm{IP}_{3}$ : Inositol 1,4,5-trisphosphate; IP $R 2$ : Inositol 1,4,5-trisphosphate receptor type 2; LTP: Long-term potentiation; mGluR: Metabotropic glutamate receptor; NMDA: N-Methyl-D-aspartate; NMDAR: N-Methyl-D-aspartate receptor; OGB-1 AM: Oregon Green ${ }^{\text {TM }} 488$ BAPTA-1 acetoxymethyl ester; RM Two-Way ANOVA: Repeated measures Two-Way analysis of variance; SD: Standard deviation; SEM: Standard error on the mean.
\end{abstract}

\section{Acknowledgements}

Two-photon imaging was performed with the equipment of Dr. Michael C Ashby (University of Bristol, UK). We thank Matt D B Claydon (University of Bristol, UK) for his comments on the manuscript.

\section{Authors' contributions}

IS, ZAB, DDB, YVDH designed research; YVDH, TS performed research; YVDH analysed data; YVDH wrote the paper. All authors revised the manuscript. All authors read and approved the final manuscript.

\section{Funding}

We would like to acknowledge the Boehringer Ingelheim Fonds and Gustave Boël_Sofina Fellowship 2018 from the King Baudouin Foundation, Platform for Education and Talent, FWO and F.R.S.-FNRS for providing travel grants. YVDH is a research fellow of the Fund for Scientific Research Flanders (FWO Grant no. 1140619N). This research was supported by the Wetenschappelijk Fonds Willy Gepts of the UZ Brussel, and the strategic research program of the Vrije Universiteit Brussel (SRP49).

\section{Availability of data and materials}

The datasets used and/or analysed during the current study are available from the corresponding author on reasonable request.

\section{Declarations}

\section{Ethics approval and consent to participate}

Ethical approval: Animal care and experimental procedures were conducted in accordance with UK Home Office regulations under the Animals (Scientific Procedures) Act of 1986

\section{Consent for publication}

Not applicable.

\section{Competing interests}

The authors declare that the research was conducted in the absence of any commercial or financial relationships that could be construed as a potential conflict of interest.

\section{Author details}

'Department of Pharmaceutical Chemistry, Drug Analysis and Drug Information, Research Group Experimental Pharmacology, Center for Neurosciences (C4N), Vrije Universiteit Brussel (VUB), Laarbeeklaan 103, 1090 Brussels,

Belgium. ${ }^{2}$ School of Physiology, Pharmacology and Neuroscience, University of Bristol, Tankard's Cl, University Walk, BS8 1TD Bristol, UK.
Received: 27 July 2021 Accepted: 11 September 2021

Published online: 20 September 2021

\section{References}

1. Shigetomi E, Patel S, Khakh BS. Probing the complexities of astrocyte calcium signaling. Trends Cell Biol. 2016;26(4):300-12.

2. Guerra-Gomes S, Sousa N, Pinto L, Oliveira JF. Functional roles of astrocyte calcium elevations: from synapses to behavior. Front Cell Neurosci. 2017;11:427.

3. Kofuji P, Araque A. G-Protein-coupled receptors in astrocyte-neuron communication. Neuroscience. 2020:456:71-84.

4. Araque A, Carmignoto G, Haydon PG, Oliet SH, Robitaille R, Volterra A. Gliotransmitters travel in time and space. Neuron. 2014;81(4):728-39.

5. Kuchibhotla KV, Lattarulo CR, Hyman BT, Bacskai BJ. Synchronous hyperactivity and intercellular calcium waves in astrocytes in Alzheimer mice. Science. 2009;323(5918):1211-5.

6. Bosson A, Boisseau S, Buisson A, Savasta M, Albrieux M. Disruption of dopaminergic transmission remodels tripartite synapse morphology and astrocytic calcium activity within substantia nigra pars reticulata. Glia. 2015:63(4):673-83.

7. Martorana F, Brambilla L, Valori CF, Bergamaschi C, Roncoroni C, Aronica $\mathrm{E}$, et al. The $\mathrm{BH} 4$ domain of $\mathrm{BCl}-\mathrm{X}(\mathrm{L})$ rescues astrocyte degeneration in amyotrophic lateral sclerosis by modulating intracellular calcium signals. Hum Mol Genet. 2012;21(4):826-40.

8. Tian GF, Azmi H, Takano T, Xu Q, Peng W, Lin J, et al. An astrocytic basis of epilepsy. Nat Med. 2005;11(9):973-81.

9. Fellin T, Gomez-Gonzalo M, Gobbo S, Carmignoto G, Haydon PG. Astrocytic glutamate is not necessary for the generation of epileptiform neuronal activity in hippocampal slices. J Neurosci. 2006;26(36):9312-22.

10. Navarrete M, Perea G, Fernandez de Sevilla D, Gomez-Gonzalo M, Nunez $A$, Martin ED, et al. Astrocytes mediate in vivo cholinergic-induced synaptic plasticity. PLoS Biol. 2012;10(2):e1001259.

11. Petravicz J, Fiacco TA, McCarthy KD. Loss of IP3 receptor-dependent $\mathrm{Ca} 2+$ increases in hippocampal astrocytes does not affect baseline CA1 pyramidal neuron synaptic activity. J Neurosci. 2008;28(19):4967-73.

12. Takata N, Mishima T, Hisatsune C, Nagai T, Ebisui E, Mikoshiba K, et al. Astrocyte calcium signaling transforms cholinergic modulation to cortical plasticity in vivo. J Neurosci. 2011;31(49):18155-65.

13. Agulhon C, Petravicz J, McMullen AB, Sweger EJ, Minton SK, Taves SR, et al. What is the role of astrocyte calcium in neurophysiology? Neuron. 2008;59(6):932-46.

14. Wettschureck N, Offermanns S. Mammalian G proteins and their cell type specific functions. Physiol Rev. 2005;85(4):1159-204.

15. Sun W, McConnell E, Pare JF, Xu Q, Chen M, Peng W, et al. Glutamatedependent neuroglial calcium signaling differs between young and adult brain. Science. 2013;339(6116):197-200.

16. Nam MH, Han KS, Lee J, Won W, Koh W, Bae JY, et al. Activation of astrocytic mu-opioid receptor causes conditioned place preference. Cell Rep. 2019:28(5):1154-66.e5.

17. Xin W, Schuebel KE, Jair KW, Cimbro R, De Biase LM, Goldman D, et al. Ventral midbrain astrocytes display unique physiological features and sensitivity to dopamine D2 receptor signaling. Neuropsychopharmacology. 2019;44(2):344-55.

18. Serrano A, Haddjeri N, Lacaille JC, Robitaille R. GABAergic network activation of glial cells underlies hippocampal heterosynaptic depression. J Neurosci. 2006;26(20):5370-82.

19. Perea G, Gomez R, Mederos S, Covelo A, Ballesteros JJ, Schlosser L, et al. Activity-dependent switch of GABAergic inhibition into glutamatergic excitation in astrocyte-neuron networks. Elife. 2016;5:e20362.

20. Jennings A, Tyurikova O, Bard L, Zheng K, Semyanov A, Henneberger C, et al. Dopamine elevates and lowers astroglial $\mathrm{Ca}(2+)$ through distinct pathways depending on local synaptic circuitry. Glia. 2017;65(3):447-59.

21. Kang J, Jiang L, Goldman SA, Nedergaard M. Astrocyte-mediated potentiation of inhibitory synaptic transmission. Nat Neurosci. 1998;1 (8):683-92.

22. Mariotti L, Losi G, Sessolo M, Marcon I, Carmignoto G. The inhibitory neurotransmitter GABA evokes long-lasting $\mathrm{Ca}(2+)$ oscillations in cortical astrocytes. Glia. 2016;64(3):363-73.

23. Gould T, Chen L, Emri Z, Pirttimaki T, Errington AC, Crunelli V, et al. GABA(B) receptor-mediated activation of astrocytes by 
gamma-hydroxybutyric acid. Philos Trans R Soc Lond B Biol Sci. 2014;369(1654):20130607.

24. Corkrum M, Rothwell PE, Thomas MJ, Kofuji P, Araque A. Opioidmediated astrocyte-neuron signaling in the nucleus accumbens. Cells. 2019;8(6):586.

25. Corkrum M, Covelo A, Lines J, Bellocchio L, Pisansky M, Loke K, et al. Dopamine-evoked synaptic regulation in the nucleus accumbens requires astrocyte activity. Neuron. 2020;105(6):1036-47.e5.

26. Meier SD, Kafitz KW, Rose CR. Developmental profile and mechanisms of GABA-induced calcium signaling in hippocampal astrocytes. Glia. 2008;56(10):1127-37.

27. Panatier A, Vallee J, Haber M, Murai KK, Lacaille JC, Robitaille R. Astrocytes are endogenous regulators of basal transmission at central synapses. Cell. 2011;146(5):785-98.

28. Min R, Nevian T. Astrocyte signaling controls spike timing-dependent depression at neocortical synapses. Nat Neurosci. 2012;15(5):746-53.

29. Henneberger C, Papouin T, Oliet SH, Rusakov DA. Long-term potentiation depends on release of D-serine from astrocytes. Nature. 2010;463(7278):232-6.

30. Martin R, Bajo-Graneras R, Moratalla R, Perea G, Araque A. Circuit-specific signaling in astrocyte-neuron networks in basal ganglia pathways. Science. 2015;349(6249):730-4.

31. Perea $G$, Araque A. Astrocytes potentiate transmitter release at single hippocampal synapses. Science. 2007:317(5841):1083-6.

32. Martin ED, Fernandez M, Perea G, Pascual O, Haydon PG, Araque A, et al. Adenosine released by astrocytes contributes to hypoxia-induced modulation of synaptic transmission. Glia. 2007:55(1):36-45.

33. Covelo A, Araque A. Neuronal activity determines distinct gliotransmitter release from a single astrocyte. Elife. 2018;7:e32237.

34. Yu X, Nagai J, Khakh BS. Improved tools to study astrocytes. Nat Rev Neurosci. 2020:21(3):121-38.

35. Eme-Scolan E, Dando SJ. Tools and approaches for studying microglia in vivo. Front Immunol. 2020;11:583647.

36. Adamsky A, Kol A, Kreisel T, Doron A, Ozeri-Engelhard N, Melcer T, et al. Astrocytic activation generates de novo neuronal potentiation and memory enhancement. Cell. 2018;174:59-71.e14.

37. Vaidyanathan TV, Collard M, Yokoyama S, Reitman ME, Poskanzer KE. Cortical astrocytes independently regulate sleep depth and duration via separate GPCR pathways. Elife. 2021;10:e63329.

38. Martin-Fernandez M, Jamison S, Robin LM, Zhao Z, Martin ED, Aguilar J, et al. Synapse-specific astrocyte gating of amygdala-related behavior. Nat Neurosci. 2017:20(11):1540-8.

39. Durkee CA, Covelo A, Lines J, Kofuji P, Aguilar J, Araque A. Gi/o proteincoupled receptors inhibit neurons but activate astrocytes and stimulate gliotransmission. Glia. 2019;67(6):1076-93.

40. Chai H, Diaz-Castro B, Shigetomi E, Monte E, Octeau JC, Yu X, et al. Neural circuit-specialized astrocytes: transcriptomic, proteomic, morphological, and functional evidence. Neuron. 2017;95(3):531-49.e9.

41. Chen N, Sugihara H, Kim J, Fu Z, Barak B, Sur M, et al. Direct modulation of GFAP-expressing glia in the arcuate nucleus bi-directionally regulates feeding. Elife. 2016:5:e18716.

42. Agulhon C, Boyt KM, Xie AX, Friocourt F, Roth BL, McCarthy KD. Modulation of the autonomic nervous system and behaviour by acute glial cell Gq protein-coupled receptor activation in vivo. J Physiol. 2013:591(22):5599-609.

43. Kol A, Adamsky A, Groysman M, Kreisel T, London M, Goshen I. Astrocytes contribute to remote memory formation by modulating hippocampal-cortical communication during learning. Nat Neurosci. 2020;23(10):1229-39.

44. Shigetomi E, Bowser DN, Sofroniew MV, Khakh BS. Two forms of astrocyte calcium excitability have distinct effects on NMDA receptormediated slow inward currents in pyramidal neurons. J Neurosci. 2008;28(26):6659-63.

45. Kilkenny C, Browne WJ, Cuthill IC, Emerson M, Altman DG. Improving bioscience research reporting: the ARRIVE guidelines for reporting animal research. J Pharmacol Pharmacother. 2010;1 (2):94-9.

46. Xie AX, Lauderdale K, Murphy T, Myers TL, Fiacco TA. Inducing plasticity of astrocytic receptors by manipulation of neuronal firing rates. J Vis Exp. 2014;85:e51458.
47. Anderson WW, Collingridge GL. Capabilities of the WinLTP data acquisition program extending beyond basic LTP experimental functions. J Neurosci Methods. 2007:162(1-2):346-56.

48. Volianskis A, Jensen MS. Transient and sustained types of long-term potentiation in the CA1 area of the rat hippocampus. J Physiol. 2003;550(Pt 2):459-92.

49. Jones ME, Paniccia JE, Lebonville CL, Reissner KJ, Lysle DT. Chemogenetic manipulation of dorsal hippocampal astrocytes protects against the development of stress-enhanced fear learning. Neuroscience. 2018:388:45-56.

50. Oe Y, Wang $X$, Patriarchi T, Konno A, Ozawa K, Yahagi K, et al. Distinct temporal integration of noradrenaline signaling by astrocytic second messengers during vigilance. Nat Commun. 2020;11(1):471.

51. Kuenzi FM, Fitzjohn SM, Morton RA, Collingridge GL, Seabrook GR Reduced long-term potentiation in hippocampal slices prepared using sucrose-based artificial cerebrospinal fluid. J Neurosci Methods. 2000;100(1-2):117-22.

52. Capron B, Sindic C, Godaux E, Ris L. The characteristics of LTP induced in hippocampal slices are dependent on slice-recovery conditions. Learn Mem. 2006;13(3):271-7.

53. Wang Y, Fu AKY, Ip NY. Instructive roles of astrocytes in hippocampal synaptic plasticity: neuronal activity-dependent regulatory mechanisms. FEBS J. 2021. https://doi.org/10.1111/febs.15878.

54. Papouin T, Dunphy J, Tolman M, Foley JC, Haydon PG. Astrocytic control of synaptic function. Philos Trans R Soc Lond B Biol Sci. 2017;372(1715):20160154.

55. Nagai J, Rajbhandari AK, Gangwani MR, Hachisuka A, Coppola G, Masmanidis SC, et al. Hyperactivity with disrupted attention by activation of an astrocyte synaptogenic cue. Cell. 2019;177(5):1280-92.e20.

56. Hur YS, Kim KD, Paek SH, Yoo SH. Evidence for the existence of secretory granule (dense-core vesicle)-based inositol 1,4,5-trisphosphate-dependent Ca2+ signaling system in astrocytes. PLoS ONE. 2010;5(8):e11973.

57. Araque A, Li N, Doyle RT, Haydon PG. SNARE protein-dependent glutamate release from astrocytes. J Neurosci. 2000;20(2):666-73.

58. Woo DH, Han KS, Shim JW, Yoon BE, Kim E, Bae JY, et al. TREK-1 and Best1 channels mediate fast and slow glutamate release in astrocytes upon GPCR activation. Cell. 2012;151(1):25-40.

59. Park H, Han KS, Seo J, Lee J, Dravid SM, Woo J, et al. Channel-mediated astrocytic glutamate modulates hippocampal synaptic plasticity by activating postsynaptic NMDA receptors. Mol Brain. 2015;8:7.

60. Woo DH, Bae JY, Nam MH, An H, Ju YH, Won J, et al. Activation of astrocytic mu-opioid receptor elicits fast glutamate release through TREK1 -containing K2P channel in hippocampal astrocytes. Front Cell Neurosci. 2018;12:319.

61. Wang F, Bradshaw HB, Pena S, Jablonska B, Xavier J, Gong S, et al. Calcium-independent astrocytic lipid release modulates neuronal excitability. 2020. Preprint available at https://www.biorxiv.org/content/10. 1101/2020.01.12.903393v5.full.

62. Lia A, Henriques VJ, Zonta M, Chiavegato A, Carmignoto G, GomezGonzalo M, et al. Calcium signals in astrocyte microdomains, a decade of great advances. Front Cell Neurosci. 2021;15:673433.

63. Sherwood MW, Arizono M, Panatier A, Mikoshiba K, Oliet SHR. Astrocytic IP3Rs: beyond IP3R2. Front Cell Neurosci. 2021:15:695817.

64. Bindocci E, Savtchouk I, Liaudet N, Becker D, Carriero G, Volterra A. Three-dimensional $\mathrm{Ca}(2+)$ imaging advances understanding of astrocyte biology. Science. 2017;356(6339):eaai8185.

65. Lohr C, Beiersdorfer A, Fischer T, Hirnet D, Rotermund N, Sauer J, et al. Using genetically encoded calcium indicators to study astrocyte physiology: a field guide. Front Cell Neurosci. 2021;15:690147.

66. Aboufares El Alaoui A, Jackson M, Fabri M, de Vivo L, Bellesi M. Characterization of subcellular organelles in cortical perisynaptic astrocytes. Front Cell Neurosci. 2020;14:573944.

67. Bashir ZI, Bortolotto ZA, Davies CH, Berretta N, Irving AJ, Seal AJ, et al. Induction of LTP in the hippocampus needs synaptic activation of glutamate metabotropic receptors. Nature. 1993;363(6427):347-50.

68. Bortolotto ZA, Collingridge GL. Activation of glutamate metabotropic receptors induces long-term potentiation. Eur J Pharmacol. 1992;214(2-3):297-8

69. Bortolotto ZA, Collett VJ, Conquet F, Jia Z, van der Putten H, Collingridge GL. The regulation of hippocampal LTP by the molecular switch, a 
form of metaplasticity, requires mGlu5 receptors. Neuropharmacology. 2005:49(Suppl 1):13-25.

70. Fujii S, Sasaki H, Mikoshiba K, Kuroda Y, Yamazaki Y, Mostafa Taufiq A, et al. A chemical LTP induced by co-activation of metabotropic and N-methylD-aspartate glutamate receptors in hippocampal CA1 neurons. Brain Res. 2004;999(1):20-8.

71. Anwyl R. Metabotropic glutamate receptor-dependent long-term potentiation. Neuropharmacology. 2009;56(4):735-40.

72. Yamazaki Y, Fujii S. Extracellular ATP modulates synaptic plasticity induced by activation of metabotropic glutamate receptors in the hippocampus. Biomed Res. 2015;36(1):1-9.
73. Yu X, Nagai J, Marti-Solano M, Soto JS, Coppola G, Babu MM, et al. Context-specific striatal astrocyte molecular responses are phenotypically exploitable. Neuron. 2020. https://doi.org/10.1016/j.neuron.2020.09.021.

74. Ouali Alami N, Tang L, Wiesner D, Commisso B, Bayer D, Weishaupt J, et al. Multiplexed chemogenetics in astrocytes and motoneurons restore blood-spinal cord barrier in ALS. Life Sci Alliance. 2020;3(11):e201900571.

\section{Publisher's Note}

Springer Nature remains neutral with regard to jurisdictional claims in published maps and institutional affiliations.
Ready to submit your research? Choose BMC and benefit from:

- fast, convenient online submission

- thorough peer review by experienced researchers in your field

- rapid publication on acceptance

- support for research data, including large and complex data types

- gold Open Access which fosters wider collaboration and increased citations

- maximum visibility for your research: over 100M website views per year

At BMC, research is always in progress.

Learn more biomedcentral.com/submissions 